\title{
EVOLUÇÃO E DETERMINANTES NA ESCOLHA DE TRABALHO ENTRE OS SETORES PÚBLICO E PRIVADO NO BRASIL
}

\author{
Daniela Verzola Vaz *
}

\begin{abstract}
Resumo
Este trabalho analisa os fatores que influenciam a decisão dos empregados em serviços no Brasil, ante a possibilidade de trabalhar no setor privado, no setor público federal, na esfera estadual ou na municipal. Além de testar o papel de um conjunto de atributos pessoais e socioeconômicos na determinação do setor de emprego, examina-se o efeito de variáveis relativas ao background familiar na alocação setorial. Os resultados mostram um efeito intergeracional, com maior probabilidade de emprego no setor público caso o pai tenha sido servidor. Esse efeito, no entanto, tem maior expressão nas esferas estadual e municipal de governo e perdeu importância, ao se compararem os dados de 1996 e de 2014.
\end{abstract}

Palavras-chave: setor público; escolha ocupacional; lógite.

\begin{abstract}
This study analyzes the factors that influence the decision of an employee of the service sector in Brazil between working in the private sector and becoming a government employee, comparing local, state, and central government levels. In addition to testing how the socioeconomic characteristics affect such choice, we investigated if variables related to the family background determine the allocation between sectors. Our findings showed an intergenerational effect, as an employee whose father has worked in the public sector is more likely to have a job in the government. This effect, however, is more relevant at state and local government levels and also has lost importance between 1996 and 2014.
\end{abstract}

Keywords: public sector; occupational choice; logit.

JEL classification: J24, C25, J45.

DOI: http://dx.doi .org/10.11606/1980-5330/ea127731

\footnotetext{
*Universidade Federal de São Paulo. E-mail: daniela.vaz@unifesp.br
} 


\section{Introdução}

O emprego no setor público, no Brasil, sempre exerceu certa atratividade sobre uma parte da população, em virtude da prerrogativa de ser estável ${ }^{1}$ e formal, características que se destacam em uma economia marcada pela instabilidade econômica.

Nos últimos anos, somou-se à garantia de estabilidade um crescente hiato salarial favorável ao setor público, tornando-o ainda mais atrativo aos olhos dos trabalhadores. Diversos estudos empíricos aplicados ao caso brasileiro mostram a existência de um prêmio salarial para os funcionários públicos, relativamente aos do setor privado (Belluzzo et al. 2005, Vaz \& Hoffmann 2007, Bender \& Fernandes 2009, Barbosa et al. 2013). Esse prêmio salarial se soma a diferenças de longo prazo nos rendimentos causadas pela diferenciação dos regimes de aposentadoria público e privado.

Pode-se afirmar, portanto, que o setor público constitui, ao menos para os trabalhadores assalariados, um segmento privilegiado do mercado de trabalho. Dessa constatação decorre uma indagação elementar: quais são os fatores fundamentais para o ingresso nesse setor de atuação? Sabe-se que o perfil dos servidores é qualitativamente superior em comparação com os trabalhadores do setor privado, pois tanto seu nível de escolaridade como sua experiência profissional são, em média, mais elevados (Ramalho \& Urani 1995, Marconi 2003). Essas diferenças descritivas ensejam o estudo do efeito das características produtivas dos trabalhadores na determinação de seu setor de emprego.

A literatura aponta que, em um contexto de alta desigualdade, a inserção dos indivíduos no mercado de trabalho depende não apenas do livre jogo da demanda e da oferta por mão de obra, mas também de outros fatores, como o background familiar e as externalidades de rede do grupo social ao qual o indivíduo pertence (IBGE 2014). As discriminações no mercado de trabalho, particularmente em relação ao gênero e à raça, também fazem com que os determinantes da inserção dos trabalhadores no mercado de trabalho transcendam suas características produtivas. Adicionalmente, as oportunidades profissionais, particularmente a possibilidade de ascender a trabalhos mais bem remunerados e que gozem de maior estabilidade, podem ser influenciadas pela família na qual o indivíduo está inserido e nas transferências culturais associadas à filiação.

Assim, tendo em vista que os trabalhadores se inserem no mercado de trabalho de forma não aleatória e sob a influência de uma gama variada de fatores, um estudo pormenorizado dos determinantes da alocação dos indivíduos entre os setores público e privado é fundamental para o conhecimento das características do mercado de trabalho do país.

O tema deste trabalho é, ainda, relevante para se compreender o papel da inserção ocupacional e setorial da mão de obra na determinação da desigualdade salarial. A mobilidade entre ocupações e setores de atividade tem sido utilizada pelos trabalhadores como forma de auferir ganhos salariais e para sair de situações precárias de trabalho, como a informalidade (Monsueto et al. 2014). Porém, se a alocação entre os setores público e privado for influenciada pelo background familiar e houver transmissão de status ocupacional entre pais e filhos, isso pode limitar a mobilidade intergeracional de renda, contri-

\footnotetext{
${ }^{1} \mathrm{O}$ Artigo 41 da Constituição brasileira assegura o direito à estabilidade ao servidor que completar três anos de efetivo exercício em cargo obtido por concurso público.
} 
buindo para a persistência das desigualdades. Note-se que o Brasil é um país com baixa mobilidade intergeracional tanto de renda (Ferreira \& Veloso 2006, Pero \& Szerman 2008) como de ocupação (Pastore \& Silva 1999).

O objetivo deste estudo é, assim, analisar os fatores que influenciam a alocação dos trabalhadores no Brasil, ante a possibilidade de trabalhar no setor privado, no setor público federal, na esfera pública estadual ou na municipal. Além de testar o papel de um conjunto de atributos pessoais e socioeconômicos na determinação do setor de emprego, examina-se o efeito de atributos relativos aos pais - a escolaridade e o setor de atuação - no modo de inserção dos indivíduos no mercado de trabalho. A hipótese subjacente é a de que haveria influência dos pais - tanto por meio da transferência do capital humano como por meio do capital cultural - na escolha setorial dos filhos.

Os dados utilizados foram extraídos da Pesquisa Nacional por Amostra de Domicílios e empregou-se o método de lógite multinomial - comumente aplicado ao estudo da escolha ocupacional dos indivíduos - para o desenvolvimento da análise. O modelo leva em conta o fato de que o setor público brasileiro é segmentado em três esferas - a saber, federal, estadual e municipal -, marcadas por diferenças substantivas quanto aos níveis de remuneração e à natureza dos postos de trabalho ofertados. Dados de 1996 e de 2014 são comparados a fim de avaliar se houve modificações no efeito das diversas variáveis ao longo desse período.

O trabalho está organizado em quatro partes, além desta introdução. Na Seção 2 são retomados artigos em que foram aplicados modelos de escolha discreta ao estudo da inserção ocupacional e setorial dos indivíduos. A seção seguinte é destinada à apresentação da base de dados e da metodologia de trabalho. Na Seção 4 são apresentados e discutidos os resultados. Para encerrar o trabalho, na última seção são sumariados os principais resultados alcançados e apresentadas as conclusões.

\section{Antecedentes}

Diversos modelos não lineares de resposta discreta já foram aplicados ao estudo da escolha ocupacional dos indivíduos, em diferentes contextos. Entre os trabalhos sobre o tema, merecem menção, por seu pioneirismo, Schmidt \& Strauss (1975) e Boskin (1974). Os primeiros estimaram lógites multinomiais para a predição do tipo de ocupação dos norte-americanos, encontrando evidências de que um maior nível de escolaridade e de experiência no mercado de trabalho aumenta a probabilidade de se ter um trabalho não braçal e com maior status social. Já Boskin (1974) mostrou, por meio de lógites condicionais, que os trabalhadores tendem a escolher as ocupações que apresentam maior valor presente dos rendimentos esperados, menores custos de treinamento e menores perdas potenciais devido ao desemprego.

Ao longo dos anos, a literatura sobre escolha ocupacional voltou-se para determinantes que vão além daqueles enunciados pela teoria do capital humano. Assim, além dos benefícios (o retorno potencial e ganhos não pecuniários) e dos custos (treinamento e retornos potenciais perdidos) envolvidos na escolha, outros fatores passaram a ser explorados, como a personalidade individual e o background familiar.

Com respeito ao background familiar, Tsukahara (2007) examinou como a escolaridade e a ocupação dos pais afetam a escolha ocupacional dos filhos no 
Japão, verificando que, principalmente em se tratando de filhos do sexo masculino, os indivíduos têm maior probabilidade de escolher a mesma ocupação de seu pai. Chevalier (2001) verificou que entre $8 \%$ e $10 \%$ dos bacharéis no Reino Unido encontram-se na mesma ocupação de seu pai de 6 a 11 anos após a formatura, o que resulta em um prêmio salarial, em relação àqueles que não seguiram a carreira paterna, de $5 \%$ a $8 \%$ para os homens, mas nulo para as mulheres. Constant \& Zimmermann (2003) verificaram que os alemães nativos escolhem ocupações semelhantes às de seus pais quando estes desempenham funções de elevado prestígio social (classificadas como white collars). Mais recentemente, Knoll et al. (2017) verificaram, também para a Alemanha, que a probabilidade relativa de um indivíduo escolher uma determinada ocupação mais que dobra se seu pai a desempenha. Essa transmissão intergeracional da escolha ocupacional, entretanto, é reduzida em cerca de $23 \%$ para os filhos de pais ausentes, o que permite creditar parte do efeito intergeracional à criação, em detrimento de fatores genéticos e inatos.

Além de explorar uma nova variedade de determinantes, a literatura sobre escolha ocupacional passou a considerar o recorte público-privado, tendo em vista as diferenças entre esses mercados de trabalho e entre os trabalhadores que os compõem. As evidências sugerem que os trabalhadores do setor público, além de guardarem diferenças em relação aos do setor privado quanto ao capital humano, seriam mais avessos ao risco (Hartog et al. 2002, Pfeifer 2011) e mais extrovertidos (Maczulskij 2017). Assim, traços da personalidade seriam determinantes adicionais da alocação nesse setor de emprego. O background familiar, por seu turno, também seria relevante, observando-se maior probabilidade de escolha de uma ocupação no setor público entre os indivíduos cujo pai trabalhou nesse setor de emprego, tanto para os trabalhadores norte-americanos (Lewis \& Frank 2002), como para os alemães (Dustmann \& Van Soest 1998). Hartog \& Oosterbeek (1993) verificaram, para a Holanda, que quanto maior a escolaridade do pai, maior a probabilidade de emprego de seu filho no setor público. Bender (2003) também reconheceu a importância das variáveis relativas ao background familiar na determinação do setor de emprego no Reino Unido, pois, ao estimar equações de salários para os trabalhadores dos setores público e privado nesse país, estimou conjuntamente uma equação de seleção setorial que controlava o setor de atuação do pai quando o indivíduo tinha 14 anos de idade ${ }^{2}$. Esse autor destaca que, embora o setor de atuação da mãe também tenha influência na escolha setorial do filho, os potenciais problemas de seleção associados à participação feminina no mercado de trabalho no passado tornariam pouco confiável a inclusão dessa variável na equação de escolha setorial.

Aplicados à realidade brasileira, os modelos de escolha ocupacional têm sido adotados com a finalidade não apenas de explorar o efeito das características pessoais e produtivas na inserção profissional dos indivíduos, mas também de verificar como as especificidades do mercado de trabalho brasileiro como o elevado grau de informalidade - e do ambiente econômico - como as imperfeições na oferta de crédito - afetam o modo de inserção dos trabalhadores. Hirata \& Machado (2010), por exemplo, verificaram que quanto mais elevada a renda domiciliar per capita no período anterior, maior é a chance de um indivíduo ser informal no período corrente, corroborando a hipótese

\footnotetext{
${ }^{2}$ Os resultados da equação de seleção não são reportados no artigo, que tem como foco comparar as distribuições de salários nos setores público e privado.
} 
de que a restrição de liquidez molda a inserção dos indivíduos no mercado de trabalho brasileiro. Ferman (2004) observou que a probabilidade de um indivíduo se tornar empregador é positivamente influenciada por sua dotação inicial de capital - captada por meio de uma proxy baseada em suas condições de moradia.

As referências na literatura nacional mais intimamente relacionadas à escolha entre atuar no setor público ou no setor privado são, ainda, escassas. Essa questão foi indiretamente explorada por Barbosa et al. (2013), ao investigarem o diferencial de salários entre os trabalhadores desses dois setores no Brasil. A fim de corrigir o viés de seleção existente na escolha dos trabalhadores - tanto com relação à decisão de participar do mercado de trabalho, como em relação à escolha do setor de atuação -, os autores estimaram um modelo de lógite multinomial para a alocação nos setores público e privado, adotando como categoria de base a não participação nesses dois mercados. Entre os resultados encontrados, merece destaque o fato de que a presença de idosos no domicílio reduz a probabilidade de entrada no setor privado, tanto para homens, como para mulheres, mas é não significativa no caso do setor público. Por outro lado, a escolaridade, principalmente o nível superior de ensino, apresenta efeitos significativos na probabilidade de ingresso de trabalhadores de ambos os sexos no setor público.

\section{Material e Métodos}

\subsection{Base de Dados}

Para a realização deste trabalho, foi utilizada a Pesquisa Nacional por Amostra de Domicílios (PNAD), conduzida pelo IBGE, referente aos anos de 1996 e 2014.

A PNAD é uma pesquisa anual baseada em uma amostra probabilística de domicílios. São investigadas diversas características socioeconômicas dos indivíduos, como educação, trabalho e rendimento, além de características gerais da população, como idade, sexo, cor, composição da família e do domicílio, migração, fecundidade etc.

A partir de 2004, a pesquisa passou a abranger todo o país, pois até então não eram coletadas informações das áreas rurais de Rondônia, Acre, Amazonas, Roraima, Pará e Amapá. Visando à comparabilidade com o ano de 1996, as informações referentes a 2014 foram filtradas de modo a representar a cobertura geográfica da pesquisa existente até 2003.

O universo de análise deste trabalho compreende os indivíduos com 10 anos ou mais de idade, economicamente ativos e que se encontram ocupados no setor de serviços, na condição de empregados ${ }^{3}$, excluindo-se os trabalhadores domésticos. Esse recorte etário leva em consideração o fato de que, embora a idade mínima para o ingresso no mercado de trabalho seja de 16 anos - cf. artigo 403 da Consolidação das Leis de Trabalho -, no mercado informal não é incomum encontrar trabalhadores abaixo dessa faixa etária.

A eliminação dos indivíduos pertencentes a ramos de atividade - no trabalho principal na semana de referência da pesquisa - ligados à agricultura e à indústria foi julgada necessária porque foi encontrado um número muito

\footnotetext{
${ }^{3}$ A PNAD inclui nessa categoria empregados com carteira, militares, funcionários públicos estatutários, outros empregados sem carteira e empregados sem declaração de carteira.
} 
pequeno de funcionários públicos em ramos de atividade primários ou secundários, para os dois anos em questão.

A variável dependente considerada - o setor do emprego no trabalho único ou principal - é uma variável categórica que assume os resultados: setor público federal, setor público estadual, setor público municipal e setor privado (adotado como base, por ser aquele com maior frequência na amostra). O setor público inclui as posições tanto de estatutário, como de celetista e sem carteira de trabalho. Nesse último caso, estão incluídos trabalhadores terceirizados, estagiários, temporários, bolsistas, consultores e outros funcionários que, embora não guardem vínculo formal com o setor público, identificam nele seu setor de atuação.

As edições de 1996 e de 2014 da PNAD contaram, em caráter excepcional, com um suplemento destinado a captar informações relativas à mobilidade sócio-ocupacional dos indivíduos, que foi aplicado a uma parcela da amostra original da pesquisa. Tais informações suplementares foram captadas, no caso de 1996, para os indivíduos de 15 anos ou mais de idade cuja condição no domicílio era pessoa de referência ou cônjuge. Na edição de 2014, o suplemento foi aplicado a moradores de 16 anos ou mais de idade selecionados aleatoriamente.

Entre as características suplementares investigadas, encontra-se, na edição de 1996, o nível de instrução do pai e da mãe. Em 2014 essa pergunta foi refinada de modo a reportar-se não necessariamente aos progenitores, mas ao homem e à mulher responsáveis, de fato, pela criação do entrevistado e que com ele coabitavam quando ele tinha 15 anos de idade. Assim, com base nessas informações, criaram-se duas variáveis binárias destinadas a captar se o pai (no caso da PNAD de 1996), ou o homem responsável pela criação e que coabitava com o entrevistado (para a PNAD de 2014), concluiu o ensino médio ${ }^{4}$ e se ele possuía instrução superior completa. Variáveis equivalentes foram construídas para captar o grau de escolaridade da mãe ou da mulher responsável pela criação.

No caso da PNAD de 2014 também foi perguntado ao morador de 16 anos ou mais de idade aleatoriamente selecionado se, quando ele tinha quinze anos de idade, seu pai ou homem responsável por sua criação era militar ou funcionário público estatutário. Com base nessa informação criou-se uma variável binária que assume valor um no caso de o pai ou responsável ser funcionário público ou militar, e valor zero em se tratando de outras ocupações, desocupação ou inatividade econômica. Para a PNAD de 1996, contudo, essa pergunta não foi realizada, tendo sido necessário construir uma proxy. Para tanto, primeiramente cruzou-se a variável indicadora de setor de emprego (V9032) com os códigos de ocupação (V9906) para todos os entrevistados da PNAD de 1996 que eram empregados ocupados em serviços. Registraram-se as ocupações nas quais se observava menos de $10 \%$ de empregados privados sobre o total, que passaram a ser consideradas ocupações predominantemente públicas. Tomou-se, então, a variável com o código de ocupação do pai quando o indivíduo entrevistado tinha 15 anos de idade (V1293) e criou-se uma variável binária que assume o valor um no caso de ocupações predominantemente públicas. Para as demais ocupações do pai, ou para os casos em que ele não trabalhava quando o indivíduo tinha quinze anos de idade, atribuiu-se o valor

\footnotetext{
${ }^{4} \mathrm{Ou}$ científico, clássico, colegial ou normal.
} 
zero a essa dummy ${ }^{5}$.

Além de variáveis relativas ao background familiar, adotaram-se controles para as características demográficas (sexo e cor) e produtivas (nível educacional e experiência profissional) e para a localização geográfica do trabalhador. Esses fatores são listados a seguir e apoiam-se na literatura revisada na Seção 2:

- Mulher: uma variável binária que assume valor zero no caso de homens e um para mulheres.

- Cor: quatro variáveis binárias para distinguir indivíduos autodeclarados brancos (tomados como base), indígenas, pretos, amarelos e pardos.

- Região: cinco variáveis binárias para distinguir seis regiões: Norte, Nordeste (base), Sul, Sudeste, Centro-Oeste (exclusive o Distrito Federal) e Distrito Federal.

- Localização do domicílio: duas variáveis binárias para caracterizar a localização do domicílio - se situado em região metropolitana, se situado em área urbana não metropolitana (categoria tomada como base) ou se situado em área rural não metropolitana.

- Experiência profissional: a experiência potencial, calculada como a diferença entre a idade corrente do indivíduo e a idade com que começou a trabalhar, medida em dezenas de anos para evitar que os coeficientes sejam muito pequenos; e a experiência potencial ao quadrado, pois não se deseja impor uma relação linear entre a probabilidade modelada e a experiência.

- Escolaridade: três variáveis binárias para identificar quatro faixas de escolaridade - analfabeto ou ensino fundamental incompleto (categoria de base), ensino fundamental completo, ensino médio completo e ensino superior completo.

- Chefe: uma variável binária para diferenciar a condição do indivíduo na família, que assume valor um para a pessoa de referência e valor zero para cônjuge, filhos e outros.

- Educação, saúde e serviços sociais: uma variável binária para diferenciar educação, saúde e serviços sociais dos demais grupamentos de atividade $^{6}$.

\footnotetext{
${ }^{5}$ Foram excluídos os indivíduos cujo pai já tinha falecido ou que não sabiam informar se o pai trabalhava quando eles tinham 15 anos de idade. Também se eliminaram os indivíduos que ignoravam o nível de instrução e setor de atuação dos progenitores ou responsáveis, bem como aqueles a quem essas perguntas não foram realizadas (por exemplo, indivíduos que não coabitaram com algum dos pais ou responsáveis pela criação, no caso da PNAD de 2014).

${ }^{6}$ A partir de 2002, a PNAD passou a adotar a Classificação Nacional de Atividades Econômicas-Domiciliar (CNAE-Domiciliar), que é uma adaptação da Classificação Nacional de Atividades Econômicas (CNAE) para as pesquisas domiciliares. A CNAE-Domiciliar apresenta diferenças importantes em relação à classificação de atividades utilizada até 2001, o que inviabiliza uma compatibilização ao nível mais desagregado entre as duas classificações. Entretanto, a Diretoria de Pesquisas do IBGE construiu uma harmonização para os grupamentos de atividade de divulgação da PNAD a partir de 2002, utilizando, além das informações mais desagregadas da antiga classificação de atividades, outras informações captadas pela pesquisa. Essa harmonização é a opção que melhor compatibiliza os grupamentos de atividades existentes antes e após 2002, sendo, por essa razão, adotada neste trabalho.
} 
- Escolaridade do pai: duas variáveis binárias para identificar o nível de instrução do pai (ou do homem responsável pela criação) - escolaridade igual ou inferior ao ensino fundamental (categoria de base), ensino médio completo e ensino superior completo.

- Escolaridade da mãe: duas variáveis binárias para identificar o nível de instrução da mãe (ou da mulher responsável pela criação) - escolaridade igual ou inferior ao ensino fundamental (categoria de base), ensino médio completo e ensino superior completo.

- Setor de emprego do pai: uma variável binária que assume valor um no caso de o pai ou responsável ser funcionário público ou militar, e valor zero em se tratando de outras ocupações, desocupação ou inatividade econômica.

Uma omissão importante, nessa lista, é a condição do trabalhador quanto à sindicalização. Nesse sentido, é pertinente observar que, no Brasil, a taxa de sindicalização dos empregados em serviços do setor público $(28,5 \%)$ é praticamente o dobro da observada no setor privado $\left(14,3 \%{ }^{7}\right)$. Assim, conforme apontado por Bender (2003), os trabalhadores que optam pelo setor público poderiam estar simultaneamente realizando a escolha por um sindicato ou por um trabalho protegido por sindicato. Por esse motivo, a atitude do trabalhador ante a sindicalização deveria ser incorporada aos regressores do modelo. Não obstante, por ter um formato de corte transversal, a PNAD não dispõe de nenhuma pergunta que capte a postura do trabalhador em relação aos sindicatos previamente à sua escolha setorial. A variável disponível informa se o trabalhador é associado ou não a algum sindicato e é contemporânea à informação referente ao setor de atuação. Assim, inclui-la no modelo poderia gerar endogeneidade, pois a opção pela sindicalização pode ser decorrência do ingresso no setor público e não anterior a ele.

\subsection{Modelo Econométrico}

Para analisar os fatores que influenciam a escolha do setor de atuação profissional dos indivíduos, empregou-se o modelo de lógite multinomial ${ }^{8}$, com quatro categorias de resposta para a variável dependente: (i) setor público federal; (ii) setor público estadual; (iii) setor público municipal; e (iv) setor privado (adotada como base). Essa especificação supõe que os empregados em serviços no Brasil realizam uma escolha simultânea, ante a possibilidade

\footnotetext{
${ }^{7}$ Percentuais calculados com base na amostra constitutiva do questionário básico da PNAD 2014, considerando-se indivíduos com 10 anos ou mais de idade, economicamente ativos e que se encontravam ocupados no setor de serviços, na condição de empregados, excluindo-se os trabalhadores domésticos.

${ }^{8}$ Cumpre destacar que modelos de lógite multinomial vêm sendo aplicados ao tratamento do viés de autosseleção amostral em equações de salários, quando esse problema envolve a decisão de alocação dos indivíduos em mais de dois estados ou setores. Nesse contexto, o procedimento empregado pressupõe, em uma primeira etapa, a estimação de equações de seleção baseadas em um modelo de lógite multinomial. No segundo estágio, adiciona-se um termo de correção - a razão inversa de Mills - às equações de salários para corrigir o problema de viés de seleção. Uma comparação dos métodos que utilizam tal procedimento pode ser encontrada em Bourguignon et al. (2007). Esses autores propõem um mecanismo alternativo de correção que leva em consideração a correlação entre os erros de cada equação de salários e os erros de cada equação lógite multinomial.
} 
de trabalhar nos setores público e privado e ante a opção de trabalhar nas áreas federal, estadual ou municipal de governo.

Esse suposto decorre da constatação de que a decisão de buscar trabalho em um determinado setor de emprego é, também, governada por preferências ocupacionais. Existem ocupações que são predominantemente ou exclusivamente oferecidas pelo setor público. Além disso, como cada esfera de governo possui atribuições constitucionais diferentes, a depender da ocupação considerada a oferta de vagas varia substancialmente de uma esfera para outra. Assim, as preferências ocupacionais dos indivíduos eventualmente somente podem ser contempladas em áreas específicas de governo. Desse modo, ao tomar a decisão de alocação setorial, os indivíduos buscariam simultaneamente contemplar suas preferências ocupacionais, de tal sorte que se veriam ante quatro possibilidades, díspares quanto à natureza das vagas oferecidas.

O modelo de lógite multinomial pressupõe a propriedade da independência de alternativas irrelevantes, segundo a qual, ante a possibilidade de escolha dentre um conjunto de alternativas mutuamente excludentes - por exemplo, $\{a, b, c\}$-, a razão de chances entre ' $a$ ' e ' $b$ ' não é afetada pela existência de ' $c$ '. Para formalizar essa propriedade, considerem-se $P_{i a}, P_{i b}$ e $P_{i c}$ as probabilidades de um determinado indivíduo escolher as alternativas ' $a$ ', ' $b$ ' (adotada como base) e ' $c$ ', respectivamente:

$$
\begin{aligned}
& P_{i a}=\frac{e^{\mathbf{X}_{\mathbf{i}} \beta_{\mathbf{a}}}}{1+e^{\mathbf{X}_{\mathbf{i}} \beta_{\mathbf{a}}}+e^{\mathbf{X}_{\mathbf{i}} \beta_{\mathbf{c}}}} \\
& P_{i b}=\frac{1}{1+e^{\mathbf{X}_{\mathbf{i}} \beta_{\mathbf{a}}}+e^{\mathbf{X}_{\mathbf{i}} \beta_{\mathbf{c}}}} \\
& P_{i c}=\frac{e^{\mathbf{X}_{\mathbf{i}} \beta_{\mathbf{c}}}}{1+e^{\mathbf{X}_{\mathbf{i}} \beta_{\mathbf{a}}}+e^{\mathbf{X}_{\mathbf{i}} \beta_{\mathbf{c}}}}
\end{aligned}
$$

em que $\mathbf{X}_{\mathbf{i}}$ é o vetor de variáveis condicionantes relativas a esse indivíduo e $\beta_{\mathbf{a}}$ e $\beta_{\mathbf{b}}$ são os vetores de coeficientes do modelo. Como se vê, $P_{i a}+P_{i b}+P_{i c}=1$.

A hipótese da independência em relação a alternativas irrelevantes - doravante IAI - estabelece que, para o indivíduo $i$, a razão de chances entre as alternativas ' $a$ ' e ' $b$ ' independe da alternativa ' $c$ ':

$$
\frac{P_{i a}}{P_{i b}}=e^{\mathbf{X}_{\mathbf{i}} \beta_{\mathbf{a}}}
$$

ou

$$
\ln \frac{P_{i a}}{P_{i b}}=\mathbf{X}_{\mathbf{i}} \beta_{\mathbf{a}}
$$

Analogamente, a razão de chances entre as alternativas ' $c$ ' e ' $b$ ' independe de ' $a$ ':

$$
\frac{P_{i c}}{P_{i b}}=e^{\mathbf{X}_{\mathbf{i}} \beta_{\mathbf{c}}}
$$


$\mathrm{ou}$

$$
\ln \frac{P_{i c}}{P_{i b}}=\mathbf{X}_{\mathbf{i}} \beta_{\mathbf{c}}
$$

A propriedade da IAI pode não ser plausível em situações nas quais as alternativas de resposta são consideradas semelhantes ${ }^{9}$. Assim, é recomendável que essa hipótese seja avaliada ao se estimar modelos de lógite multinomial. Hausman \& McFadden (1984) e Small \& Hsiao (1985) propuseram testes para verificar se essa hipótese deve ou não ser rejeitada.

As Equações 4 e 5 mostram que o modelo de lógite multinomial pode ser visto como a estimação simultânea de lógites binomiais para todos os pares de resultados possíveis para a variável dependente. Enquanto a estimação eficiente do modelo requer que todos os pares sejam estimados simultaneamente, o que impõe certas restrições lógicas entre os parâmetros, estimativas consistentes, porém ineficientes, podem ser obtidas estimando-se uma série de lógites binários (Cheng \& Long 2007). Os testes para IAI propostos por Hausman \& McFadden (1984) e Small \& Hsiao (1985) partem desse princípio e adotam a seguinte estratégia: para cada alternativa de resposta da variável dependente, eliminam-se da amostra os indivíduos que escolheram aquela alternativa e reestima-se o modelo com as alternativas remanescentes - obtendo-se, assim, um modelo restrito. Na sequência, conduz-se um teste para comparar as novas estimativas com as originais, obtidas a partir da amostra completa. Sob a hipótese nula de IAI, as estimativas obtidas a partir do modelo restrito são consistentes, porém ineficientes, devendo ser preteridas em prol do modelo completo, que provê estimativas não apenas consistentes, como também eficientes.

Foram conduzidos os testes de Hausman e McFadden e Small e Hsiao ${ }^{10}$ sob quatro variantes do modelo restrito: ora excluindo-se o setor público federal da amostra, ora o estadual, o municipal e, por fim, o privado. Os resultados encontram-se reportados na Tabela 5, no Apêndice. Para o ano de 2014, observam-se resultados estatisticamente significativos para o teste de Small e Hsiao, o que permitiria rejeitar a hipótese de IAI. No caso do teste

\footnotetext{
${ }^{9}$ Um exemplo em que a IAI é irrealista é proposto por McFadden (1974, apud Wooldridge (2002)). Supõe-se que um indivíduo dispõe de duas alternativas de transporte - automóvel ou onibus vermelho -, com igual probabilidade de escolha $\left(\frac{1}{2}\right)$, de tal maneira que a razão de chances entre elas é 1 . Posteriormente, surge uma terceira alternativa: ônibus azul. Admitindo que a cor do ônibus é irrelevante para a decisão desse indivíduo sobre o meio de transporte, a probabilidade de escolher entre ônibus vermelho e azul é a mesma. Adicionalmente, devido à hipótese da IAI, a razão de chances entre as probabilidades de escolha de automóvel e ônibus vermelho deve permanecer sendo igual a 1. Para isso ocorrer, a probabilidade de escolha de cada meio de transporte passará a ser de $\frac{1}{3}$; ou seja, a hipótese de IAI implica que a probabilidade de escolha do automóvel como meio de transporte se reduz de $\frac{1}{2}$ para $\frac{1}{3}$ quando o indivíduo passa a ter a opção do ônibus azul, além do vermelho, o que é implausível, já que a cor do ônibus é irrelevante. Nesse caso, portanto, o lógite subestimaria a probabilidade de escolha do automóvel como meio de transporte.

${ }^{10}$ Para computar o teste de Small-Hsiao é necessário dividir a amostra aleatoriamente em dois subconjuntos (ver Small \& Hsiao (1985)). A variável utilizada para tal foi uma dummy igual a um caso o indivíduo tenha nascido em um mês ímpar. Caso essa variável não tivesse sido especificada, o comando 'smhsiao', do Stata - programa utilizado para realizar este trabalho teria aleatoriamente formado as subamostras, o que dificultaria a replicação dos resultados deste artigo, pois a cada vez que o comando fosse rodado novas subamostras seriam obtidas.
} 
de Hausman e McFadden, no entanto, as estatísticas de teste são frequentemente não significativas ou negativas, o que seria evidência de que a hipótese de IAI se sustenta. Tal inconsistência nos resultados tem sido observada por alguns autores - como Cheng \& Long (2007) e Long \& Freese (2014) - e alimentado críticas em relação a esses testes ${ }^{11}$ : "tests of the IIA assumption that are based on the estimation of a restricted choice set are unsatisfactory for applied work" (Cheng \& Long 2007). Em lugar de sua utilização, sugere-se a adoção das recomendações de McFadden (1974, apud Cheng \& Long (2007) e Long \& Freese (2014), para quem o lógite multinomial somente deve ser adotado nos casos em que as categorias de resposta possam ser consideradas distintas aos olhos do tomador de decisão.

No caso do presente estudo, evidências sugerem que, aos olhos do trabalhador, é plausível considerar as esferas federal, estadual e municipal do setor público como não equivalentes. Além das diferenças quanto à natureza das vagas oferecidas, essas áreas de governo apresentam grandes disparidades em termos remuneratórios. Najberg et al. (2002) mostram que os funcionários federais têm remuneração média 1,9 vezes maior que os estaduais, e esses, uma média 1,7 vezes maior que os funcionários municipais. Belluzzo et al. (2005) e Foguel et al. (2000) mostram, por meio de estratégias de estimação distintas, que o prêmio salarial no setor público, relativamente ao setor privado, é heterogêneo, sendo superior na esfera federal que nas outras áreas de governo.

Cabe observar, ainda, que o interior do setor público é marcado por um conjunto díspar de regimes previdenciários - com diferenças substanciais entre os militares e os funcionários públicos estatutários dos três níveis de governo. As diferenças quanto às alíquotas e ao tempo de contribuição, bem como em relação ao valor do benefício também contribuem para que essas esferas de governo não sejam consideradas substitutas aos olhos dos trabalhadores.

\section{Resultados e Discussão}

Após eliminar as observações para as quais faltava alguma informação relevante para a análise, obteve-se uma amostra de 19.526 indivíduos para o ano de 1996 e de 7.235 indivíduos em 2014, os quais, expandidos segundo os pesos fornecidos pela pesquisa ${ }^{12}$, correspondem a, respectivamente, $8.789 .818 \mathrm{e}$ 4.103.634 pessoas. Sua distribuição segundo setor de emprego é apresentada

\footnotetext{
${ }^{11}$ Cheng \& Long (2007) realizaram simulações de Monte Carlo com o objetivo de avaliar o tamanho dos testes mais utilizados para IAI, dentre os quais os de Small e Hsiao e Hausman e McFadden. As simulações são realizadas considerando tanto regressores contínuos como categóricos e diferentes tamanhos de amostra, além de diferentes estruturas de dados - por exemplo, com diferentes graus de multicolinearidade entre os regressores, diferentes valores para as estimativas dos parâmetros e baixa frequência de valores nas tabulações cruzadas entre regressores binários e a variável dependente. Os autores concluem que esses testes têm um desempenho bastante insatisfatório. No caso do teste de Hausman e McFadden, o tamanho empírico do teste frequentemente não converge para o valor nominal, mesmo em amostras grandes, isto é, a probabilidade efetiva de rejeitar a hipótese nula quando ela é verdadeira é frequentemente diferente do nível de significância adotado. A magnitude dessa discrepância varia enormemente segundo a estrutura dos dados. Além disso, a estatística de teste é frequentemente negativa. O teste de Small e Hsiao tem propriedades de tamanho razoáveis para alguns conjuntos de dados, mas apresenta severas distorções em seu tamanho quando há baixa frequência de valores nas tabulações cruzadas entre regressores binários e a variável dependente, mesmo em amostras grandes.

${ }^{12}$ Para a PNAD de 1996 foram utilizados os fatores de expansão divulgados juntamente com a PNAD de 1997, os quais foram corrigidos com base na contagem populacional de 1996.
} 
na Tabela 1, a seguir. Observa-se, em termos relativos, um crescimento da ocupação no setor público municipal $(+22,9 \%)$ e no setor privado $(+12,2 \%)$ entre 1996 e 2014. Como consequência, diminuiu o peso dos empregados federais e estaduais no universo de análise considerado.

Tabela 1: Distribuição dos empregados em serviços, segundo setor de emprego, Brasil, 1996/2014

\begin{tabular}{l|r|r|r}
\hline & \multicolumn{2}{|c|}{ Distribuição (\%) } & \multirow{2}{*}{ Variação (\%) } \\
\cline { 2 - 3 } & \multicolumn{1}{|c|}{$\mathbf{1 9 9 6}$} & \multicolumn{1}{c|}{$\mathbf{2 0 1 4}$} & \\
\hline Setor público federal & 7,07 & 4,82 & $-31,82$ \\
Setor público estadual & 19,91 & 11,48 & $-42,34$ \\
Setor público municipal & 16,55 & 20,34 & 22,90 \\
Setor privado & 56,47 & 63,36 & 12,20 \\
\hline Total & 100,00 & 100,00 & \\
\hline
\end{tabular}

Fonte: Microdados da PNAD. Elaboração própria.

Tanto para 1996, quanto para 2014, dois modelos foram ajustados: um sem as variáveis relativas ao background familiar (Modelo 1), e outro que incorpora esse componente à análise (Modelo 2) por meio de cinco variáveis binárias, destinadas a captar indivíduos: cujo pai (ou homem responsável pela criação) (1) era funcionário público; (2) concluiu o ensino médio; (3) possuía instrução superior; e cuja mãe (ou mulher responsável pela criação) (4) tinha ensino médio; (5) possuía instrução superior.

As informações relativas à qualidade do ajustamento e as probabilidades estimadas pelo lógite encontram-se reportadas na Tabela 2.

Tabela 2: Probabilidades calculadas e medidas de qualidade do ajustamento, Brasil, 1996/2014

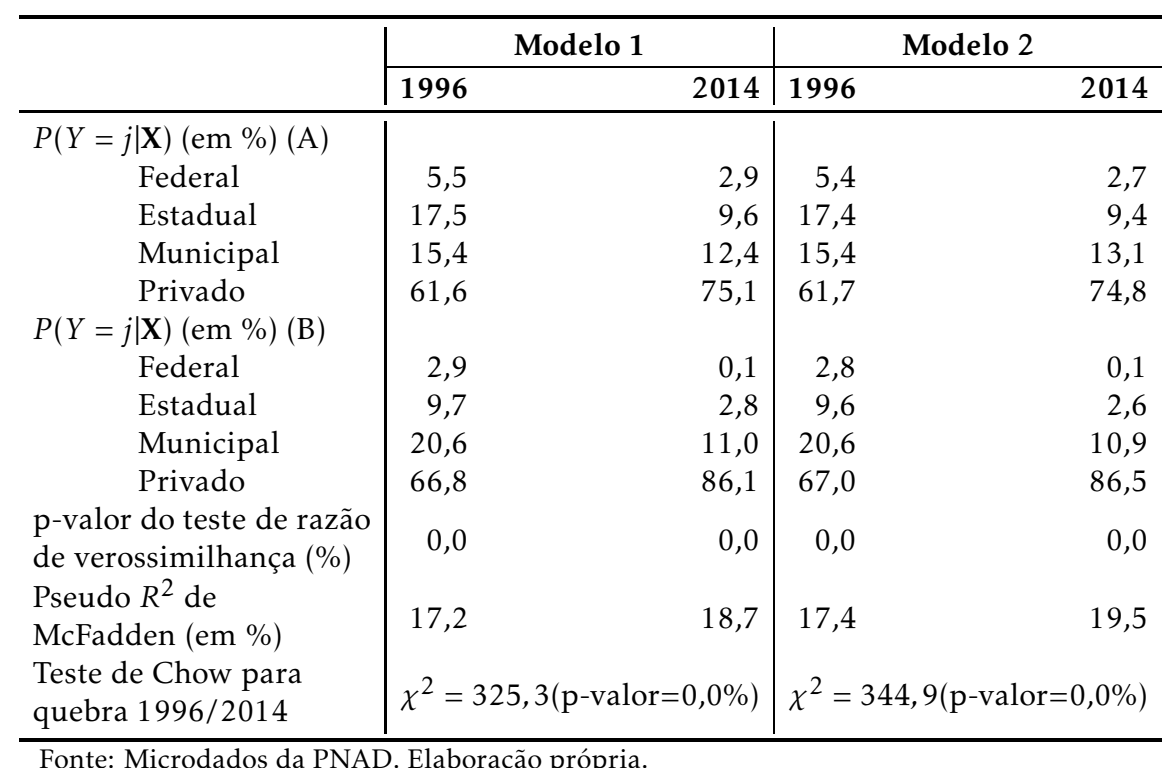

A probabilidade de um indivíduo ocupado no setor de serviços trabalhar no setor $j$ foi calculada de duas maneiras diferentes. Primeiro, considerando 
o ponto médio das variáveis explanatórias, inclusive das binárias (A). Em seguida, considerando a categoria de base das variáveis binárias e, para as variáveis experiência potencial e experiência potencial ao quadrado, o valor médio e o seu quadrado, respectivamente (B). Independentemente da forma de cálculo adotada, observa-se que, entre 1996 e 2014, a probabilidade de trabalhar no setor público diminuiu nas três áreas de emprego consideradas, em face do aumento da probabilidade de emprego no setor privado.

Em ambos os anos e considerando os dois modelos ajustados, o resultado obtido para o teste de razão de verossimilhança foi significativo, o que permite refutar a hipótese de nulidade conjunta dos parâmetros. Assim, o conjunto de regressores adotado é pertinente para explicar a alocação setorial dos trabalhadores em serviços. O teste de Chow indica haver quebra estrutural entre os anos de 1996 e 2014, o que justifica a estimativa em separado dos modelos para esses dois anos.

O pseudo coeficiente de determinação (pseudo $R^{2}$ ) mostra um melhor ajuste dos modelos para o ano de 2014. Cabem, entretanto, algumas observações. Primeiro, é preciso notar que essa medida não pode ser interpretada como a proporção da variabilidade total da variável dependente explicada pelo modelo. O coeficiente de determinação aqui apresentado corresponde à adaptação de McFadden ${ }^{13}$ para modelos não lineares estimados por máxima verossimilhança. Sua escala de variação modifica-se de acordo com o modelo que está sendo estimado, o que impede comparações com outros trabalhos. Portanto, mais importantes que o $R^{2}$, nesse caso, são a significância estatística das variáveis explanatórias e seus efeitos marginais.

Ainda com relação à qualidade do ajustamento, não se pode deixar de observar que a determinação do setor de trabalho no qual um indivíduo irá atuar depende de uma série de fatores que não foram captados pelas variáveis explanatórias consideradas neste trabalho, por diversas razões. Por um lado, há dificuldades para mensurar a importância que os indivíduos conferem às características do emprego público vis-à-vis do privado, por exemplo, estabilidade, sistema de previdência social etc. Essas preferências determinam o empenho pessoal em alocar-se em um ou outro setor. Por outro lado, certos atributos importantes para o sucesso na tentativa de ingresso na carreira pública, como habilidade para sair-se bem nas provas ou rede de contatos profissionais em caso de cargos que não são preenchidos mediante concurso, como os cargos comissionados, não são captados pelas pesquisas socioeconômicas disponíveis.

O modelo de lógite multinomial estima um vetor de parâmetros para cada categoria de resposta da variável dependente (exclusive a categoria de base, que, neste caso, é o setor privado). Foram conduzidos testes de razão de verossimilhança para a hipótese de que os coeficientes desses diferentes vetores que estão associados a um mesmo regressor são simultaneamente nulos, isto é, $\beta_{h, f e d}=\beta_{h, e s t}=\beta_{h, \text { mun }}$, em que $h=1,2, \ldots, k$ denota um determinado regressor do modelo e os subscritos $\{f e d, e s t, m u n\}$ indicam à qual dos vetores estimados o coeficiente pertence. Os resultados, reportados na Tabela 6, no Apêndice, mostram que no ano de 2014 não são significativos, sequer ao nível de significância de $10 \%$, os conjuntos de coeficientes associados às variáveis

\footnotetext{
${ }^{13} \mathrm{O}$ pseudo $R^{2}$ de McFadden é dado por $1-\frac{\ln \hat{L}\left(M_{c o m p l}\right)}{\ln \hat{L}\left(M_{i n t}\right)}$, em que $\hat{L}\left(M_{i n t}\right)$ é a função estimada de verossimilhança para o modelo que contém apenas o intercepto e $\hat{L}\left(M_{\text {compl }}\right)$ é a estimativa da verossimilhança para o modelo completo.
} 
binárias para pretos e para amarelos. Em 1996 também não há significância estatística dos coeficientes associados a indígenas e às variáveis que captam a escolaridade da mãe do indivíduo. No caso das binárias para cor, a ausência de significância estatística pode estar relacionada ao reduzido tamanho amostral de algumas categorias de resposta entre os funcionários públicos particularmente aquelas relativas a amarelos e indígenas.

Conduziu-se, ainda, o teste de razão de verossimilhança para a combinação de categorias de resposta da variável dependente (Tabela 7, no Apêndice). Sob a hipótese nula desse teste, duas categorias de resposta - por exemplo, setor público federal e estadual -, seriam idênticas com relação às variáveis do modelo, de maneira que o efeito de cada variável explanatória sobre a razão de chances entre elas seria não significativo. Assim, obter-se-iam estimativas dos coeficientes mais eficientes se elas fossem aglutinadas. Verifica-se que, para todos os anos e modelos, o teste foi significativo ao nível de $1 \%$ para todas as combinações possíveis de categorias de resposta, indicando que nenhuma das alternativas de setor de emprego deve ser incorporada a outra.

Os coeficientes estimados dos modelos, para ambos os anos, encontramse reportados nas Tabelas 8 e 9, no Apêndice. Os efeitos marginais dos regressores do modelo que inclui as variáveis relativas ao background familiar (Modelo 2) são reportados nas Tabelas 3 e 4, a seguir. Eles foram calculados considerando-se as categorias de base das variáveis binárias - a saber, indivíduo do sexo masculino, branco, residente em área urbana da região Nordeste, que não é a pessoa de referência na família, não trabalha no ramo de atividade de educação, saúde e serviços sociais e não concluiu o ensino fundamental. Para as variáveis experiência potencial e experiência potencial ao quadrado, foram atribuídos o valor médio da experiência potencial e o seu quadrado, respectivamente.

Constata-se que o fato de o pai ter sido servidor público exerce um efeito positivo e estatisticamente significativo na probabilidade de seu filho também o ser, relativamente ao emprego no setor privado, confirmando as evidências encontradas por Lewis \& Frank (2002) e Dustmann \& Van Soest (1998). Tal efeito, no entanto, tem maior magnitude em âmbito estadual e municipal e perdeu importância entre 1996 e 2014, tendo inclusive desaparecido em nível federal. Essa diferença intertemporal nos resultados pode ter duas explicações: primeiro, ela pode ser decorrência da mudança na metodologia de captação das informações do suplemento de mobilidade sócio-ocupacional da PNAD. Enquanto em 1996 a informação se referia exclusivamente ao pai, independentemente de este coabitar com o filho ou não, em 2014 a informação passou a referir-se ao homem responsável pela criação e que necessariamente morava com o respondente quando esse tinha 15 anos de idade. Outra explicação para esse resultado seria, de fato, a perda de importância desse aspecto do background familiar na determinação do setor de emprego, ao se compararem os dados de 1996 e de 2014.

No que se refere ao nível de instrução paterna, merece destaque o fato de que se o pai concluiu o ensino médio a probabilidade de emprego de seu filho no setor público municipal, relativamente ao setor privado, é menor. O fato de o pai ter ensino superior também reduz essa chance, embora o efeito somente seja significativo em 2014 (-4,4 p.p.). Esses resultados destoam daqueles encontrados por Hartog \& Oosterbeek (1993) para a Holanda e sugerem que, no Brasil, os servidores da esfera municipal advêm de famílias com menor capital humano. 
Tabela 3: Efeitos marginais (em pontos percentuais), Modelo 2, Brasil, 1996

\begin{tabular}{l|rl|rl|rl}
\hline Variável & \multicolumn{2}{|c|}{ Federal } & Estadual & Municipal \\
\hline Mulher & $-0,98$ & $* * *$ & 0,16 & & 10,01 & $* * *$ \\
Experiência & 2,08 & $* * *$ & 6,99 & $* * *$ & 3,83 & $* * *$ \\
Experiência ao quadrado & $-0,31$ & $* * *$ & $-0,83$ & $* * *$ & $-0,01$ & \\
Indígena & 4,07 & & $-4,63$ & & $-0,90$ & \\
Preto & 1,30 & $* *$ & 0,69 & & $-0,89$ & \\
Amarelo & 0,12 & & $-1,57$ & & $-9,63$ & $* *$ \\
Pardo & 0,19 & & 1,39 & $* * *$ & 2,15 & $* *$ \\
Norte & 2,19 & $* * *$ & 2,03 & $* *$ & $-4,91$ & $* * *$ \\
Sudeste & $-1,48$ & $* * *$ & $-3,93$ & $* * *$ & $-7,48$ & $* * *$ \\
Sul & $-1,41$ & $* * *$ & $-4,01$ & $* * *$ & $-5,16$ & $* * *$ \\
Centro-Oeste exclusive DF & $-0,25$ & & $-2,31$ & $* * *$ & $-7,57$ & $* * *$ \\
Distrito Federal & 6,82 & $* * *$ & 9,25 & $* * *$ & $-20,32$ & $* * *$ \\
Ensino fundamental completo & 5,00 & $* * *$ & 7,64 & $* * *$ & $-3,15$ & $* * *$ \\
Ensino médio completo & 11,55 & $* * *$ & 21,22 & $* * *$ & $-5,25$ & $* * *$ \\
Ensino superior completo & 20,26 & $* * *$ & 26,60 & $* * *$ & $-5,82$ & $* * *$ \\
Região metropolitana & 0,23 & & $-3,46$ & $* * *$ & $-10,45$ & $* * *$ \\
Área rural não metropolitana & $-0,16$ & & 1,25 & & 15,68 & $* * *$ \\
Chefe & 0,52 & $* *$ & $-0,50$ & & $-3,86$ & $* * *$ \\
Educação, saúde e serviços sociais & $-0,36$ & $*$ & 14,28 & $* * *$ & 16,75 & $* * *$ \\
Setor de atuação do pai & 0,78 & $*$ & 6,51 & $* * *$ & 3,87 & $*$ \\
Pai com ensino médio & 0,83 & $* *$ & $-0,62$ & & $-4,67$ & $* * *$ \\
Pai com ensino superior & 1,47 & $* * *$ & $-1,13$ & & 2,31 & \\
Mãe com ensino médio & 0,59 & $*$ & 0,70 & & $-1,26$ & \\
Mãe com ensino superior & $-0,61$ & & $-0,62$ & & $-3,51$ & \\
\hline Nota* & & &
\end{tabular}

Nota: ${ }^{* * *},{ }^{* *} \mathrm{e}$ * denotam os efeitos estatisticamente significativos aos níveis de $1 \%$, $5 \%$ e $10 \%$, respectivamente.

Fonte: Microdados da PNAD. Elaboração própria.

O nível de instrução paterna tem um efeito muito pequeno na chance de emprego em nível federal, se considerado o ano de 1996, ou estatisticamente não significativo, se tomado o ano de 2014. No entanto, se em lugar de se considerar um indivíduo que não concluiu o ensino fundamental para o cálculo dos efeitos marginais, considerar-se um indivíduo com ensino superior completo (mantidas as categorias de base das demais variáveis binárias), o efeito da instrução paterna passa a ter um efeito considerável: da ordem de 5,9 p.p., caso o pai detenha ensino médio completo, e de 8,1 p.p., se ele tem ensino superior, em 2014, com significância estatística ao nível de 1\%. Isso sugere que a origem social do trabalhador afeta sua chance de ingresso na carreira pública federal - que é justamente a que oferece, em média, as melhores condições de remuneração no serviço público.

Considerando um indivíduo que não concluiu o ensino fundamental, os efeitos marginais associados à escolaridade da mãe somente foram estatisticamente significativos, ao nível de 5\%, para o ano de 2014 e ao se estimar a probabilidade de emprego em nível municipal (conforme Tabela 4). Verificase que, tudo o mais constante, tal probabilidade aumenta em 2,4 p.p., se a mãe detinha o ensino médio completo, e em 5,4 p.p. se ela possuía o diploma universitário.

Independentemente da categoria das variáveis binárias adotada para o cál- 
Tabela 4: Efeitos marginais (em pontos percentuais), Modelo 2, Brasil, 2014

\begin{tabular}{|c|c|c|c|c|c|}
\hline Variável & Federal & Estadu & & Munici & pal \\
\hline Mulher & $-0,03$ & $-0,39$ & * & 4,63 & $* * *$ \\
\hline Experiência & 0,00 & 1,67 & $* * *$ & 5,51 & *** \\
\hline Experiência ao quadrado & 0,00 & $-0,12$ & * & $-0,32$ & ** \\
\hline Indígena & 0,06 & 9,89 & & $-10,87$ & *** \\
\hline Preto & 0,01 & $-0,15$ & & 1,29 & \\
\hline Amarelo & 0,01 & $-2,01$ & $* * *$ & $-1,47$ & \\
\hline Pardo & 0,00 & $-0,14$ & & 2,49 & $* * *$ \\
\hline Norte & 0,06 & 2,42 & $* * *$ & $-1,09$ & \\
\hline Sudeste & $-0,02$ & $-0,98$ & $* * *$ & $-5,04$ & $* * *$ \\
\hline Sul & 0,00 & $-0,88$ & ** & $-4,24$ & *** \\
\hline Centro-Oeste exclusive DF & $-0,01$ & 0,64 & & $-3,64$ & *** \\
\hline Distrito Federal & 0,33 & 3,71 & $* *$ & $-10,87$ & *** \\
\hline Ensino fundamental completo & $1,67^{* * *}$ & 0,06 & & 1,14 & \\
\hline Ensino médio completo & 2,54 & 5,44 & $* * *$ & 7,42 & $* * *$ \\
\hline Ensino superior completo & 6,76 & 16,98 & $* * *$ & 14,06 & *** \\
\hline Região metropolitana & 0,02 & $-0,69$ & $* * *$ & $-6,58$ & *** \\
\hline Área rural não metropolitana & $-0,04$ & 0,46 & & 11,98 & *** \\
\hline Chefe & 0,01 & 0,97 & $* * *$ & 1,90 & ** \\
\hline Educação, saúde e serviços sociais & 0,00 & 3,68 & $* * *$ & 20,04 & *** \\
\hline Setor de atuação do pai & 0,01 & 2,25 & $* * *$ & 2,64 & * \\
\hline Pai com ensino médio & 0,05 & $-0,11$ & & $-3,13$ & *** \\
\hline Pai com ensino superior & 0,07 & 0,35 & & $-4,43$ & *** \\
\hline Mãe com ensino médio & 0,02 & 0,60 & & 2,39 & ** \\
\hline Mãe com ensino superior & 0,03 & 0,77 & & 5,44 & ** \\
\hline
\end{tabular}

Nota: ${ }^{* * *},{ }^{* *} \mathrm{e}^{*}$ denotam os efeitos estatisticamente significativos aos níveis de $1 \%, 5 \%$ e $10 \%$, respectivamente.

Fonte: Microdados da PNAD. Elaboração própria.

culo dos efeitos marginais do modelo, constatam-se efeitos contrários das escolaridades do pai e da mãe sobre a probabilidade de emprego em nível municipal: enquanto o fato de a mãe ter ensino superior eleva a probabilidade de emprego nesse segmento, o fato de o pai ter ensino superior a reduz. Esses dois efeitos se referem ao ano de 2014, o que permite excluir a possibilidade de que essa diferença se deva a questões metodológicas. Assim, vê-se que a influência do pai e da mãe, por meio de sua escolaridade, na escolha de setor de emprego dos filhos pode ser diferente. Os mecanismos por meio dos quais a escolaridade dos pais afetaria o desempenho dos filhos no mercado de trabalho estariam relacionados a variáveis não observadas relativas à escolarização dos indivíduos, como a eficiência do aprendizado e a qualidade da educação recebida. Outro canal por meio do qual esse efeito se daria estaria associado à capacidade de pais mais escolarizados, e assim mais ricos, alocarem seus filhos em melhores empregos (Schultz 1988). Uma base de dados que também contenha informação sobre a ocupação da mãe poderá oferecer insights adicionais sobre as causas da diferença observada.

Com relação aos demais regressores do modelo, adotados como controles, os maiores efeitos são observados para as variáveis que captam a escolaridade do trabalhador, particularmente o ensino superior completo. Segundo a Tabela 4, em 2014 ter concluído o ensino superior elevava a probabilidade de 
alocação nos setores públicos federal, estadual e municipal em 6,8, 17,0 e 14,1 p.p., respectivamente, em relação ao emprego no setor privado, supondo os demais fatores constantes. Esse resultado reflete, em grande medida, a existência de requisitos mínimos de formação para o ingresso no serviço público: para o exercício de diversas atribuições exige-se educação superior. Contudo, cabe notar que, entre 1996 e 2014, a magnitude do efeito da escolaridade sobre a probabilidade de emprego nas esferas federal e estadual, relativamente ao emprego no setor privado, reduziu-se. Esse resultado indica que também no setor privado elevaram-se os requisitos de formação para contratação, o que somente foi possível porque aumentou a oferta de mão de obra qualificada no mercado de trabalho de uma maneira geral. Conforme apontado pelo Instituto de Pesquisa Econômica Aplicada (IPEA 2013), a oferta de trabalhadores com pelo menos o ensino superior completo apresentou aceleração em seu crescimento ao longo dos anos 2000, ao passo que a expansão do grupo com ensino médio completo sofreu uma inflexão já a partir do final dos anos 1990.

Para emprego como funcionário público municipal, porém, o efeito da escolaridade é distinto: enquanto em 1996 um maior grau de escolaridade implicava menor probabilidade de emprego nessa área de governo, relativamente ao emprego no setor privado, em 2014 o ensino médio e o ensino superior passaram a ter grande influência para a inserção no serviço público municipal. No caso do indivíduo aqui adotado como referência para o cálculo dos efeitos marginais, a conclusão do ensino médio eleva em 7,4 p.p. a probabilidade de emprego no setor público municipal, ao passo que o diploma superior eleva em 14,1 p.p. essa chance. Embora, dentre as esferas de governo, a municipal seja a que apresenta a menor escolaridade média da força de trabalho, ela é justamente a que apresentou os avanços mais significativos nesse quesito entre 2002 e 2010 (IPEA 2011).

Ser mulher influi positivamente para o emprego no setor público municipal, mesmo controlando-se os ramos de atividade econômica de educação, saúde e serviços sociais, nos quais elas são maioria. Em 1996, a magnitude do efeito era de 10,0 p.p., reduzindo-se para 4,6 p.p. em 2014. A preferência feminina pela esfera pública municipal, relativamente ao emprego no setor privado, é sugestiva tanto de uma maior aversão ao risco de desemprego por parte das mulheres, como da antecipação de situações de discriminação por elas vivenciadas no setor privado. Além da maior estabilidade no emprego, em relação ao setor privado, o Estado prima pela maior transparência em seus processos de seleção de pessoal e pela isonomia de vencimentos para cargos com atribuições iguais ou assemelhadas. A primeira dessas práticas é garantida pela obrigatoriedade de realização de concursos públicos para contratação de servidores, introduzida por ocasião da Constituição Federal de 1988. A segunda é prevista em lei. Ambas têm potencial para coibir práticas discriminatórias contra as mulheres, à medida que buscam assegurar igual oportunidade de inserção profissional a indivíduos portadores de um mesmo conjunto de atributos produtivos e promover a padronização dos critérios de remuneração.

Em âmbito federal e estadual, no entanto, o efeito do sexo do indivíduo, embora de magnitude muito reduzida, é negativo ${ }^{14}$. Esse comportamento dis-

\footnotetext{
${ }^{14} \mathrm{O}$ teste de Chow indica haver diferença estrutural no modelo ajustado separadamente para homens e mulheres, tanto em 1996 como para 2014.
} 
sonante merece atenção, por ser justamente nessas esferas de governo que se encontram os cargos de maior prestígio e remuneração no setor público. A literatura tem mostrado que não é incomum as mulheres se autoexcluírem dos cargos de liderança, e mesmo de carreiras de maior prestígio e remuneração, em razão da interiorização de normas de socialização que pregam a necessidade de serem atenciosas e prestativas - qualidades conflitantes com a ambição profissional. Adicionalmente, porque desejam evitar os obstáculos e conflitos que anteveem para conciliar suas vidas profissionais e familiares, e que normalmente são potencializados nas posições de comando e nas carreiras de maior prestígio (Lombardi 2008, Georges 2008, Vaz 2013).

O efeito da cor na escolha setorial indica que ser pardo eleva a probabilidade do emprego público municipal, relativamente ao emprego no setor privado. Embora esse efeito seja de baixa magnitude, da ordem de 2,0 p.p., ele é observado nos dois anos estudados. Esse comportamento, tal como no caso das mulheres, é sugestivo de uma maior aversão ao risco de desemprego por parte de grupos que são alvo de discriminação no mercado de trabalho.

Residir em área rural eleva a probabilidade de emprego no setor público municipal em 15,7 p.p., para o ano de 1996, e 12,0 p.p. em 2014, relativamente ao emprego no setor privado. Para entender esses efeitos, cabe relembrar que o objeto de análise desta pesquisa são os empregados em serviços. Esse ramo de atividade econômica, considerando-se a posição de empregado, é menos desenvolvido no meio rural, em que se estrutura, em grande medida, em torno do serviço público. Em contrapartida, nas regiões metropolitanas as alternativas de trabalho no setor terciário são tantas que o emprego público acaba por representar uma fração menor das possibilidades existentes.

O emprego no ramo de educação, saúde e serviços sociais eleva substancialmente a probabilidade de emprego no setor público municipal, sendo pouco influente na probabilidade de emprego em nível federal. Além disso, o efeito dessa variável para a chance de emprego em nível estadual reduziu-se de 14,3 p.p. para 3,7 p.p. entre 1996 e 2014 . Esses resultados refletem, em certa medida, o processo de descentralização administrativa introduzido pela Constituição Federal de 1988 e que se estendeu ao longo dos anos 1990, resultando na especialização dos municípios na provisão de serviços de atendimento à saúde e na oferta da educação em nível infantil e fundamental.

\section{Considerações Finais}

Este artigo procurou analisar os fatores que influenciam a decisão dos empregados em serviços no Brasil, ante a possibilidade de trabalhar no setor privado, no setor público federal, na esfera pública estadual ou na municipal. Um modelo de lógite multinomial foi estimado com base nos dados das PNAD de 1996 e de 2014, incorporando como variáveis explanatórias, além de atributos pessoais e socioeconômicos dos indivíduos, regressores relativos ao background familiar.

Os resultados mostram que existe influência do setor de atuação do pai na decisão sobre o setor de atuação dos filhos, particularmente em nível estadual e municipal. Esse resultado encontra-se em consonância com a literatura que reporta o papel dos pais na escolha profissional dos indivíduos.

O nível de instrução paterna tem efeito na alocação setorial dos trabalhadores, o que sugere que a origem social do indivíduo afeta sua inserção. Em 
termos de políticas públicas, é importante conhecer os fatores que podem minimizar a importância desse efeito.

Merecem destaque os efeitos contrários que as escolaridades do pai e da mãe exercem sobre a probabilidade de emprego em nível municipal: enquanto o fato de a mãe ter ensino superior eleva a probabilidade de emprego nesse segmento, o fato de o pai ter ensino superior reduz essa probabilidade. Os mecanismos por meio dos quais a escolaridade dos pais afetaria o desempenho dos filhos no mercado de trabalho estariam relacionados a variáveis não observadas relativas à escolarização dos indivíduos, como a eficiência do aprendizado e a qualidade da educação recebida. Outro canal por meio do qual esse efeito se daria estaria associado à capacidade de pais mais escolarizados, e assim mais ricos, alocarem seus filhos em melhores empregos. Trabalhos futuros sobre o tema poderão investigar melhor esses canais de influência, a fim de se compreenderem as diferenças observadas nos efeitos da escolaridade paterna e materna sobre a escolha setorial dos indivíduos.

\section{Referências Bibliográficas}

Barbosa, A. L. N. H., Barbosa Filho, F. H. \& Lima, J. R. F. (2013), 'Diferencial de salários e determinantes na escolha de trabalho entre os setores público e privado no Brasil', Pesquisa e Planejamento Econômico 43(1), 89-118.

URL: http://ppe.ipea.gov.br/index.php/ppe/article/view/1405/1127

Belluzzo, W., Anuatti-Neto, F. \& Pazello, E. T. (2005), 'Distribuição de salários e o diferencial público-privado no Brasil', Revista Brasileira de Economia 59, 511-533.

Bender, K. A. (2003), 'Examining equality between public- and private-sector wage distributions', Economic Inquiry 41(1), 62-79.

URL: https://onlinelibrary.wiley.com/doi/abs/10.1093/ei/41.1.62

Bender, S. \& Fernandes, R. (2009), 'Gastos públicos com pessoal: uma análise de emprego e salário no setor público brasileiro nos anos 90', Economia 10(1), 19-47.

Boskin, M. J. (1974), 'A conditional Logit model of occupational choice', Journal of Political Economy 82(2), 389-398.

URL: $h t t p: / / w w w . j s t o r . o r g / s t a b l e / 1831185$

Bourguignon, F., Fournier, M. \& Gurgand, M. (2007), 'Selection bias corrections based on the multinomial logit model: Monte Carlo comparisons', Journal of Economic Surveys 21(1), 174-205.

URL: $\quad$ https://onlinelibrary.wiley.com/doi/abs/10.1111/j.1467-

6419.2007.00503.x

Cheng, S. \& Long, J. S. (2007), 'Testing for IIA in the multinomial Logit model', Sociological Methods E Research 35(4), 583-600.

URL: https://doi.org/10.1177/0049124106292361

Chevalier, A. (2001), Just like daddy: the occupational choice of UK graduates, in 'Royal Economic Society Annual Conference 2002', number 47, Royal Economic Society. 
Constant, A. \& Zimmermann, K. F. (2003), 'Occupational choice across generations'. IZA Discussion Paper n. 975.

Dustmann, C. \& Van Soest, A. (1998), 'Public and private sector wages of male workers in Germany', European Economic Review 42(8), 1417-1441.

Ferman, B. (2004), 'Imperfeições no mercado de crédito e escolha ocupacional: o que mudou no Brasil com a estabilização da economia?', Monografia Prêmio IPEA/Caixa. 42 p.

Ferreira, S. G. \& Veloso, F. A. (2006), 'Intergenerational mobility of wages in Brazil', Brazilian Review of Econometrics 26(2), 181-211.

Foguel, M. N., Gill, I., Mendonça, R. \& Barros, R. P. (2000), 'The publicprivate wage gap in Brazil', Revista Brasileira de Economia 54(4), 433-472.

Georges, I. (2008), Entre vida doméstica e vida profissional: engenheiras no Brasil e na França, in A. O. Costa, ed., 'Mercado de trabalho e gênero: comparações internacionais', editora FGV, Rio de Janeiro, chapter 13, pp. 245-261.

Hartog, J., Ferrer-I-Carbonell, A. \& Jonker, N. (2002), 'Linking measured risk aversion to individual characteristics', Kyklos 55(1), 3-26.

Hartog, J. \& Oosterbeek, H. (1993), 'Public and private sector wages in the Netherlands', European Economic Review 37(1), 97-114.

Hausman, J. A. \& McFadden, D. (1984), 'Specification tests for the multinomial Logit model', Econometrica 52(5), 1219-1240.

Hirata, G. I. \& Machado, A. F. (2010), 'Escolha ocupacional e transição no Brasil metropolitano: uma análise com ênfase no setor informal', Economia Aplicada 14(4), 299-322.

IBGE (2014), 'Pesquisa Nacional por Amostra de Domicílios - mobilidade sócio-ocupacional: 2014’. IBGE.

URL: http://biblioteca.ibge.gov.br/visualizacao/livros/liv98815.pdf

IPEA (2011), 'Ocupação no setor público brasileiro: tendências recentes e questões em aberto'. (Comunicados do IPEA n. 110).

URL: $h t t p: / / w w w . i p e a . g o v . b r / p o r t a l / i m a g e s / s t o r i e s / P D F s / c o m u n i c a d o / 110$ 908_comunicadoipea110.pdf

IPEA (2013), 'Um retrato de duas décadas do mercado de trabalho brasileiro utilizando a PNAD'. (Comunicados do IPEA n. 160).

URL: $h t t p s: / / w w w . i p e a . g o v . b r / p o r t a l / i m a g e s / s t o r i e s / P D F s / c o m u n i c a d o / 131$ 007_comunicadoipea160.pdf

Knoll, B., Riedel, N. \& Schlenker, E. (2017), 'He's a chip off the old block - the persistence of occupational choices across generations', Labour 31(2), 174203.

Lewis, G. B. \& Frank, S. A. (2002), 'Who wants to work for the government?', Public Administration Review 62(4), 395-404. 
Lombardi, M. R. (2008), Engenheira e gerente: desafios enfrentados por mulheres em posições de comando na área tecnológica, in A. O. e. a. Costa, ed., 'Mercado de trabalho e gênero: comparações internacionais', Vol. 1, editora FGV.

Long, J. S. \& Freese, J. (2014), Regression Models for Categorical Dependent Variables Using Stata, 3 edn, Stata Press.

Marconi, N. (2003), 'A evolução do perfil da força de trabalho e das remunerações nos setores público e privado ao longo da década de 1990', Revista do Serviço Público 54(1), 7-43.

Monsueto, S. E., Bichara, J. S. \& Cunha, A. M. (2014), 'Occupational mobility and income differentials: the experience of Brazil between 2002 and 2010', Cepal Review (113), 139-155.

Najberg, S., Moraes, R. M. \& Ikeda, M. (2002), 'Participação dos empregos do setor público no mercado de trabalho', Informe-se (42). $8 \mathrm{p}$.

URL: $h t t p: / / w w w . b n d e s . g o v . b r / S i t e B N D E S / e x p o r t / s i t e s / d e f a u l t / b n d e s \_p t /$

Galerias/Arquivos/conhecimento/informesf/Inf_42.pdf

Pastore, J. \& Silva, N. V. (1999), Mobilidade Social no Brasil, 1 edn, Makron Books.

Pero, V. \& Szerman, D. (2008), 'Mobilidade intergeracional de renda no Brasil', Pesquisa e Planejamento Econômico 38(1).

Pfeifer, C. (2011), 'Risk aversion and sorting into public sector employment', German Economic Review 12(1), 85-99.

Ramalho, M. \& Urani, A. (1995), 'A administração pública como empregadora: uma avaliação da década de 80’. (Série Seminários IPEA n. 5).

Schmidt, P. \& Strauss, R. P. (1975), 'The prediction of occupation using multiple Logit models', International Economic Review 16(2), 471-486.

Schultz, T. P. (1988), Education investments and returns., in H. Chenery \& T. N. Scrinivasan, eds, 'Handbook of development economics', Vol. 1, North Holland Publishing Company, Amsterdam, chapter 13, pp. 543-630.

Small, K. A. \& Hsiao, C. (1985), 'Multinomial Logit specification tests', International Economic Review 26(3), 619-627.

Tsukahara, I. (2007), 'The effect of family background on occupational choice', Labour 21(4-5), 871-890.

Vaz, D. V. (2013), 'O teto de vidro nas organizações públicas: evidências para o Brasil', Economia e Sociedade 22(3), 765-790.

Vaz, D. V. \& Hoffmann, R. (2007), 'Remuneração nos serviços nos anos 90: o contraste entre funcionários públicos e privados', Economia e Sociedade 16(2), 199-232.

Wooldridge, J. M. (2002), Econometric Analysis of Cross Sections and Panel Data, 1 edn, The MIT Press. 


\section{Apêndice}


Tabela 5: Testes de Hausman-McFadden e Small-Hsiao para a independência de alternativas irrelevantes, Brasil, 1996/2014

\begin{tabular}{|c|c|c|c|c|c|c|c|c|c|}
\hline \multirow{6}{*}{ Teste } & \multirow{6}{*}{ Exclusão } & \multicolumn{4}{|c|}{1996} & \multicolumn{4}{|c|}{2014} \\
\hline & & \multirow{2}{*}{\multicolumn{2}{|c|}{$\begin{array}{c}\text { Sem variáveis } \\
\text { relativas ao }\end{array}$}} & \multicolumn{2}{|c|}{\begin{tabular}{|c|} 
Com variáveis \\
\end{tabular}} & \multicolumn{2}{|c|}{ Sem variáveis } & \multicolumn{2}{|c|}{ Com variáveis } \\
\hline & & & & \multirow{2}{*}{\multicolumn{2}{|c|}{$\begin{array}{l}\text { relativas ao } \\
\text { background }\end{array}$}} & \multirow{2}{*}{\multicolumn{2}{|c|}{$\begin{array}{l}\text { relativas ao } \\
\text { hackoround }\end{array}$}} & \multicolumn{2}{|c|}{ relativas ao } \\
\hline & & \multicolumn{2}{|c|}{ background } & & & & & \multirow{2}{*}{\multicolumn{2}{|c|}{$\begin{array}{c}\text { background } \\
\text { familiar } \\
\end{array}$}} \\
\hline & & \multicolumn{2}{|c|}{ familiar } & \multicolumn{2}{|c|}{ familiar } & \multicolumn{2}{|c|}{ familiar } & & \\
\hline & & $x^{2}$ & $\begin{array}{c}\text { p-valor } \\
(\%)\end{array}$ & $x^{2}$ & $\begin{array}{c}\text { p-valor } \\
(\%)\end{array}$ & $x^{2}$ & $\begin{array}{c}\text { p-valor } \\
(\%)\end{array}$ & $x^{2}$ & $\begin{array}{c}\text { p-valor } \\
(\%)\end{array}$ \\
\hline \multirow{4}{*}{$\begin{array}{l}\text { Hausman e } \\
\text { McFadden }\end{array}$} & Federal & 60,6 & 1,9 & 77,1 & 0,8 & 0,0 & & 0,0 & \\
\hline & Estadual & 42,9 & 34,7 & 16,9 & 100,0 & 0,0 & 100,0 & 0,0 & \\
\hline & Municipal & $-163,6$ & & $-87,1$ & & 60,2 & 2,1 & 56,5 & 24,6 \\
\hline & Privado & $-2.874,3$ & & $-3.517,9$ & & $-95,4$ & & $-91,9$ & \\
\hline \multirow{4}{*}{ Small-Hsiao } & Federal & $-116,2$ & 100,0 & $-103,3$ & 100,0 & 327,0 & 0,0 & 365,1 & $\overline{0,0}$ \\
\hline & Estadual & 132,2 & 0,0 & 148,5 & 0,0 & 503,0 & 0,0 & 590,2 & 0,0 \\
\hline & Municipal & 853,5 & 0,0 & 872,3 & 0,0 & 710,9 & 0,0 & 788,3 & 0,0 \\
\hline & Privado & 388,6 & 0,0 & 398,0 & 0,0 & 263,7 & 0,0 & 301,6 & 0,0 \\
\hline \multicolumn{2}{|c|}{$\begin{array}{c}\text { Amostra } \\
\text { Amostra expandida }\end{array}$} & \multicolumn{4}{|c|}{$\begin{array}{c}19.526 \\
8.789 .818\end{array}$} & \multicolumn{4}{|c|}{$\begin{array}{c}7.235 \\
4.103 .634\end{array}$} \\
\hline
\end{tabular}

Fonte: Microdados da PNAD. Elaboração própria. 
Tabela 6: Estatística de teste e probabilidade caudal dos testes de razão de verossimilhança para os regressores do modelo, Brasil, 1996 e 2014

\begin{tabular}{|c|c|c|c|c|c|c|c|c|}
\hline \multirow{3}{*}{ Variável } & \multicolumn{4}{|c|}{ Modelo 1} & \multicolumn{4}{|c|}{ Modelo 2} \\
\hline & \multicolumn{2}{|c|}{1996} & \multicolumn{2}{|c|}{2014} & \multicolumn{2}{|c|}{1996} & \multicolumn{2}{|c|}{2014} \\
\hline & $\chi^{2}$ & $\begin{array}{c}\text { p-valor } \\
(\%)\end{array}$ & $\chi^{2}$ & $\begin{array}{c}\text { p-valor } \\
(\%)\end{array}$ & $x^{2}$ & $\begin{array}{c}\text { p-valor } \\
(\%)\end{array}$ & $x^{2}$ & $\begin{array}{c}\text { p-valor } \\
(\%)\end{array}$ \\
\hline Mulher & 89,0 & 0,0 & 78,1 & 0,0 & 87,9 & 0,0 & 70,2 & 0,0 \\
\hline Experiência & 219,4 & 0,0 & 71,5 & 0,0 & 219,3 & 0,0 & 69,4 & 0,0 \\
\hline Quadrado da experiência & 90,4 & 0,0 & 18,2 & 0,0 & 91,6 & 0,0 & 16,8 & 0,1 \\
\hline Indígena & 2,0 & 57,3 & 7,4 & 5,9 & 2,2 & 52,3 & 8,0 & 4,5 \\
\hline Preto & 5,9 & 11,5 & 2,3 & 52,1 & 7,3 & 6,3 & 2,3 & 51,7 \\
\hline Amarelo & 5,0 & 16,9 & 6,2 & 10,2 & 5,0 & 17,3 & 6,5 & 8,9 \\
\hline Pardo & 18,3 & 0,0 & 12,7 & 0,5 & 16,9 & 0,1 & 10,1 & 1,7 \\
\hline Norte & 38,9 & 0,0 & 23,1 & 0,0 & 37,6 & 0,0 & 23,0 & 0,0 \\
\hline Sudeste & 236,7 & 0,0 & 73,4 & 0,0 & 234,4 & 0,0 & 67,4 & 0,0 \\
\hline Sul & 127,1 & 0,0 & 30,7 & 0,0 & 125,0 & 0,0 & 29,6 & 0,0 \\
\hline Centro-Oeste exclusive DF & 44,7 & 0,0 & 14,2 & 0,3 & 43,9 & 0,0 & 14,1 & 0,3 \\
\hline Distrito Federal & 148,3 & 0,0 & 91,7 & 0,0 & 148,7 & 0,0 & 89,4 & 0,0 \\
\hline Ensino fundamental completo & 192,6 & 0,0 & 27,8 & 0,0 & 187,0 & 0,0 & 28,3 & 0,0 \\
\hline Ensino médio completo & $1.351,4$ & 0,0 & 140,1 & 0,0 & $1.268,8$ & 0,0 & 127,7 & 0,0 \\
\hline Ensino superior completo & $1.898,4$ & 0,0 & 479,2 & 0,0 & $1.584,2$ & 0,0 & 377,4 & 0,0 \\
\hline Região metropolitana & 385,6 & 0,0 & 190,3 & 0,0 & 377,3 & 0,0 & 173,9 & 0,0 \\
\hline Área rural não metropolitana & 107,4 & 0,0 & 42,1 & 0,0 & 108,3 & 0,0 & 41,4 & 0,0 \\
\hline Pessoa de referência na família & 21,3 & 0,0 & 21,8 & 0,0 & 21,2 & 0,0 & 18,8 & 0,0 \\
\hline Educação, saúde e serviços sociais & $1.156,5$ & 0,0 & 400,8 & 0,0 & $1.153,8$ & 0,0 & 396,1 & 0,0 \\
\hline Setor de atuação do pai & & & & & 55,8 & 0,0 & 29,6 & 0,0 \\
\hline Pai com ensino médio & & & & & 15,1 & 0,2 & 27,4 & 0,0 \\
\hline Pai com ensino superior & & & & & 16,7 & 0,1 & 30,6 & 0,0 \\
\hline Mãe com ensino médio & & & & & 4,2 & 24,2 & 9,4 & 2,4 \\
\hline Mãe com ensino superior & & & & & 3,9 & 27,1 & 12,2 & 0,7 \\
\hline
\end{tabular}

Fonte: Microdados da PNAD. Elaboração própria. 
Tabela 7: Estatística de teste e probabilidade caudal dos testes de razão de verossimilhança para combinação de alternativas de resposta da variável dependente, Brasil, 1996 e 2014

\begin{tabular}{|c|c|c|c|c|c|c|c|c|}
\hline & \multicolumn{4}{|c|}{ Modelo 1} & \multicolumn{4}{|c|}{ Modelo 2} \\
\hline & \multicolumn{2}{|c|}{1996} & \multicolumn{2}{|c|}{2014} & \multicolumn{2}{|c|}{1996} & \multicolumn{2}{|c|}{2014} \\
\hline & $x^{2}$ & $\begin{array}{c}\text { p-valor } \\
(\%)\end{array}$ & $x^{2}$ & $\begin{array}{c}\text { p-valor } \\
(\%)\end{array}$ & $x^{2}$ & $\begin{array}{c}\text { p-valor } \\
(\%)\end{array}$ & $\chi^{2}$ & $\begin{array}{c}\text { p-valor } \\
(\%)\end{array}$ \\
\hline $\begin{array}{l}\text { Federal \& } \\
\text { estadual }\end{array}$ & 712,3 & 0,0 & 237,7 & 0,0 & 733,3 & 0,0 & 261,3 & 0,0 \\
\hline $\begin{array}{l}\text { Federal \& } \\
\text { municipal }\end{array}$ & $2.068,8$ & 0,0 & 736,0 & 0,0 & $2.090,3$ & 0,0 & 793,7 & 0,0 \\
\hline $\begin{array}{l}\text { Federal \& } \\
\text { privado }\end{array}$ & $2.234,1$ & 0,0 & 704,2 & 0,0 & $2.277,5$ & 0,0 & 764,4 & 0,0 \\
\hline $\begin{array}{l}\text { Estadual \& } \\
\text { municipal }\end{array}$ & $1.263,4$ & 0,0 & 377,0 & 0,0 & $1.279,5$ & 0,0 & 410,3 & 0,0 \\
\hline $\begin{array}{l}\text { Estadual \& } \\
\text { Privado }\end{array}$ & $4.472,9$ & 0,0 & $1.278,1$ & 0,0 & $4.529,2$ & 0,0 & $1.321,8$ & 0,0 \\
\hline $\begin{array}{l}\text { Municipal \& } \\
\text { Privado }\end{array}$ & $2.677,6$ & 0,0 & $1.420,8$ & 0,0 & $2.703,0$ & 0,0 & $1.426,0$ & 0,0 \\
\hline
\end{tabular}

Fonte: Microdados da PNAD. Elaboração própria. 
Tabela 8: Coeficientes estimados para o lógite multinomial sem variáveis relativas ao background familiar (Modelo 1), Brasil, 1996/2014

\begin{tabular}{|c|c|c|c|c|c|c|c|c|c|c|c|c|}
\hline \multirow{2}{*}{ Variável } & \multicolumn{6}{|c|}{1996} & \multicolumn{6}{|c|}{2014} \\
\hline & \multicolumn{2}{|c|}{ Federal } & \multicolumn{2}{|c|}{ Estadual } & \multicolumn{2}{|c|}{ Municipal } & \multicolumn{2}{|c|}{ Federal } & \multicolumn{2}{|c|}{ Estadual } & \multicolumn{2}{|c|}{ Municipal } \\
\hline Mulher & $-0,30$ & $* * *$ & 0,15 & $* *$ & 0,54 & $* * *$ & $-0,74$ & $* * *$ & $-0,15$ & * & 0,40 & $* * *$ \\
\hline iência & 0,88 & $* * *$ & 0,93 & $* * *$ & 0,39 & $* * *$ & $-0,18$ & & 0,66 & $* * *$ & 0,59 & $* * *$ \\
\hline iência ao quadrado & $-0,12$ & $* * *$ & $-0,11$ & $* * *$ & $-0,02$ & * & 0,08 & $* * *$ & $-0,04$ & $* *$ & $-0,03$ & $* *$ \\
\hline Indíge & 0,76 & & $-0,71$ & & $-0,07$ & & 0,35 & & 1,45 & * & $-12,95$ & \\
\hline Preto & 0,35 & $* *$ & 0,10 & & $-0,02$ & & 0,12 & & $-0,08$ & & 0,14 & \\
\hline Amarelo & $-0,11$ & & $-0,35$ & & $-0,78$ & $* *$ & 0,12 & & $-1,53$ & $* *$ & $-0,26$ & \\
\hline Pardo & 0,10 & & 0,20 & $* * *$ & 0,16 & $* * *$ & $-0,08$ & & $-0,06$ & & 0,24 & $* * *$ \\
\hline & 0,58 & $* * *$ & 0,17 & * & $-0,29$ & $* * *$ & 0,71 & $* * *$ & 0,67 & $* * *$ & $-0,10$ & \\
\hline & $-0,93$ & *** & $-0,71$ & $* * *$ & $-0,63$ & $* * *$ & $-0,41$ & $* *$ & $-0,57$ & $* * *$ & $-0,72$ & $* * *$ \\
\hline Sul & $-0,86$ & $* * *$ & $-0,69$ & $* * *$ & $-0,43$ & $* * *$ & $-0,06$ & & $-0,50$ & $* * *$ & $-0,56$ & $* * *$ \\
\hline Cen & $-0,24$ & * & $-0,43$ & $* * *$ & $-0,60$ & $* * *$ & $-0,19$ & & 0,16 & & $-0,46$ & $* * *$ \\
\hline & 1,16 & $* * *$ & 0,61 & $* * *$ & $-4,31$ & $* * *$ & 1,84 & $* * *$ & 0,86 & $* * *$ & $-23,01$ & \\
\hline Ens & 1,19 & $* * *$ & 0,75 & $* * *$ & $-0,01$ & & 3,43 & $* * *$ & 0,07 & & 0,14 & \\
\hline & 2,22 & $* * *$ & 1,72 & $* * *$ & 0,22 & $* * *$ & 4,13 & $* * *$ & 1,39 & $* * *$ & 0,72 & $* * *$ \\
\hline & 3,20 & $* * *$ & 2,30 & $* * *$ & 0,59 & $* * *$ & 5,79 & $* * *$ & 2,76 & $* * *$ & 1,41 & $* * *$ \\
\hline & $-0,05$ & & $-0,63$ & $* * *$ & $-0,89$ & $* * *$ & 0,35 & $* * *$ & $-0,35$ & $* * *$ & $-1,03$ & $* * *$ \\
\hline Área rural não metropolitana & 0,23 & & 0,40 & $* * *$ & 0,85 & $* * *$ & $-1,26$ & & 0,24 & & 0,88 & $* * *$ \\
\hline & 0,11 & & $-0,11$ & * & $-0,26$ & $* * *$ & 0,31 & ** & 0,38 & $* * *$ & 0,20 & $* * *$ \\
\hline & 0,45 & $* * *$ & 1,52 & $* * *$ & 1,20 & $* * *$ & 0,24 & * & 1,21 & $* * *$ & 1,37 & $* * *$ \\
\hline Constante & $-4,53$ & $* * *$ & $-3,52$ & $* * *$ & $-1,98$ & $* * *$ & $-7,09$ & $* * *$ & $-4,59$ & $* * *$ & $-3,11$ & $* * *$ \\
\hline
\end{tabular}

Nota: ${ }^{* * *},{ }^{* *} \mathrm{e}^{*}$ denotam os coeficientes estatisticamente significativos aos níveis de $1 \%, 5 \%$ e $10 \%$, respectivamente.

Fonte: Microdados da PNAD. Elaboração própria. 
Tabela 9: Coeficientes estimados para o lógite multinomial com variáveis relativas ao background familiar (Modelo 2), Brasil, 1996/2014

\begin{tabular}{|c|c|c|c|c|c|c|c|c|c|c|c|c|}
\hline \multirow{2}{*}{ Variável } & \multicolumn{6}{|c|}{1996} & \multicolumn{6}{|c|}{2014} \\
\hline & \multicolumn{2}{|c|}{ Federal } & \multicolumn{2}{|c|}{ Estadual } & \multicolumn{2}{|c|}{ Municipal } & \multicolumn{2}{|c|}{ Federal } & \multicolumn{2}{|c|}{ Estadual } & \multicolumn{2}{|c|}{ Municipal } \\
\hline Mulher & $-0,28$ & $* * *$ & 0,16 & $* *$ & 0,54 & $* * *$ & $-0,68$ & $* * *$ & $-0,12$ & & 0,40 & $* * *$ \\
\hline Experiência & 0,93 & $* * *$ & 0,92 & $* * *$ & 0,38 & $* * *$ & 0,02 & & 0,73 & $* * *$ & 0,59 & $* * *$ \\
\hline Experiência ao quadrado & $-0,13$ & $* * *$ & $-0,10$ & $* * *$ & $-0,02$ & & 0,06 & ** & $-0,05$ & $* *$ & $-0,03$ & $* *$ \\
\hline Indígena & 0,87 & & $-0,69$ & & $-0,07$ & & 0,69 & & 1,57 & ** & $-13,22$ & \\
\hline Preto & 0,40 & $* * *$ & 0,09 & & $-0,03$ & & 0,24 & & $-0,05$ & & 0,13 & \\
\hline Amarelo & $-0,11$ & & $-0,33$ & & $-0,78$ & $* *$ & 0,08 & & $-1,58$ & ** & $-0,18$ & \\
\hline & 0,12 & & 0,19 & $* * *$ & 0,16 & $* * *$ & 0,06 & & $-0,03$ & & 0,23 & $* * *$ \\
\hline Norte & 0,57 & $* * *$ & 0,18 & * & $-0,28$ & $* * *$ & 0,72 & $* * *$ & 0,68 & $* * *$ & $-0,09$ & \\
\hline Sudeste & $-0,92$ & $* * *$ & $-0,71$ & $* * *$ & $-0,63$ & $* * *$ & $-0,40$ & $* *$ & $-0,55$ & $* * *$ & $-0,69$ & $* * *$ \\
\hline Sul & $-0,84$ & $* * *$ & $-0,69$ & $* * *$ & $-0,43$ & $* * *$ & $-0,01$ & & $-0,48$ & $* * *$ & $-0,55$ & $* * *$ \\
\hline Centro- & $-0,23$ & * & $-0,42$ & $* * *$ & $-0,60$ & $* * *$ & $-0,18$ & & 0,19 & & $-0,44$ & $* * *$ \\
\hline Dist & 1,17 & $* * *$ & 0,62 & $* * *$ & $-4,30$ & $* * *$ & 1,85 & $* * *$ & 0,82 & $* * *$ & $-19,85$ & \\
\hline & 1,17 & $* * *$ & 0,74 & $* * *$ & $-0,01$ & & 3,47 & $* * *$ & 0,06 & & 0,13 & \\
\hline Ens & 2,16 & $* * *$ & 1,70 & $* * *$ & 0,23 & $* * *$ & 4,03 & $* * *$ & 1,34 & $* * *$ & 0,72 & $* * *$ \\
\hline & 3,05 & $* * *$ & 2,28 & $* * *$ & 0,62 & $* * *$ & 5,38 & $* * *$ & 2,61 & $* * *$ & 1,40 & $* * *$ \\
\hline Região & $-0,11$ & & $-0,64$ & $* * *$ & $-0,89$ & $* * *$ & 0,24 & * & $-0,40$ & $* * *$ & $-1,01$ & $* * *$ \\
\hline Área & 0,23 & & 0,41 & $* * *$ & 0,85 & $* * *$ & $-1,12$ & & 0,32 & & 0,90 & $* * *$ \\
\hline Chef & 0,12 & & $-0,11$ & * & $-0,26$ & $* * *$ & 0,26 & $* *$ & 0,35 & $* * *$ & 0,19 & $* * *$ \\
\hline Educaçã & 0,47 & $* * *$ & 1,53 & $* * *$ & 1,21 & $* * *$ & 0,25 & * & 1,21 & $* * *$ & 1,37 & $* * *$ \\
\hline Setor & 0,43 & $* * *$ & 0,70 & $* * *$ & 0,35 & $* * *$ & 0,21 & & 0,69 & $* * *$ & 0,28 & $* *$ \\
\hline Pai com e & 0,19 & * & $-0,13$ & & $-0,32$ & $* * *$ & 0,59 & $* * *$ & $-0,08$ & & $-0,38$ & $* * *$ \\
\hline & 0,46 & $* * *$ & $-0,09$ & & 0,15 & & 0,77 & $* * *$ & 0,08 & & $-0,57$ & $* * *$ \\
\hline Mãe com ensino médio & 0,19 & * & 0,07 & & $-0,06$ & & 0,36 & $* *$ & 0,25 & $* *$ & 0,23 & $* *$ \\
\hline Mãe com ensino superior & $-0,31$ & * & $-0,14$ & & $-0,25$ & & 0,55 & $* *$ & 0,34 & * & 0,48 & $* * *$ \\
\hline Constante & $-4,66$ & $* * *$ & $-3,54$ & $* * *$ & $-1,96$ & $* * *$ & $-7,65$ & $* * *$ & $-4,80$ & $* * *$ & $-3,13$ & $* * *$ \\
\hline
\end{tabular}

Nota: ${ }^{* * *},{ }^{* *} \mathrm{e}^{*}$ denotam os coeficientes estatisticamente significativos aos níveis de $1 \%, 5 \%$ e $10 \%$, respectivamente.

Fonte: Microdados da PNAD. Elaboração própria. 
